\title{
Análise microbiológica da placa bacteriana da doença periodontal em cães e o efeito da antibioticoterapia sobre ela
}

\author{
Microbiological analysis of bacterial plaque of periodontal disease on dogs and effects of \\ antibioticotherapy on it
}

\author{
Stella Alves da Fonseca ${ }^{I^{*}}$ Paula Diniz Galera $^{\mathrm{I}}$ Daiana Lima Brito \\ Simone Perecmanis ${ }^{I}$ Anahí Souza Silva ${ }^{I}$ Larissa Borges Cardoso ${ }^{I}$ Tatiana Guerrero Marçola ${ }^{I}$ \\ Vinícius Oliveira Drummond ${ }^{\mathrm{I}}$ Concepta McManus Pimentel ${ }^{\mathrm{I}}$
}

\begin{abstract}
RESUMO
Objetivou-se determinar a microbiota da placa bacteriana subgengival de cães com doença periodontal (DP) e estabelecer o efeito da antibioticoterapia. Avaliaram-se 20 cães com graus variados de DP e coletaram-se amostras da placa bacteriana subgengival antes e após antibioticoterapia. Preconizou-se antibioticoterapia distinta em dois grupos, com 10 animais cada: clindamicina (G1) e metronidazol + espiramicina (G2). Observou-se crescimento bacteriano subgengival na maioria dos cães com DP e correlação entre a severidade da DP e a idade dos animais. Houve redução significativa no crescimento bacteriano após a antibioticoterapia e o antibiograma demonstrou maior sensibilidade à clindamicina, seguido da espiramicina; todos os microrganismos foram resistentes ao metronidazol.
\end{abstract}

Palavras-chave: doença periodontal, placa bacteriana, cães, antibioticoterapia, clindamicina, metronidazol, espiramicina.

\section{ABSTRACT}

The objective was to determine microbiote of the subgingival bacterial plaque of dogs with periodontal disease $(P D)$ and establish the effect of antibioticotherapy on its reduction. Twenty dogs with varied stages of $P D$ were evaluated and samples of their subgingival bacterial plaque were collected. Distinct antibiotic protocols were used in two groups with ten animals each: clindamycin (G1) and metronidazole + espiramycin (G2). New subgingival samples were collected 15 days after antibiotic therapy started. There were observed subgingival bacterial culture on most dogs with PD and correlation between severity of $P D$ and age. There was reduction of bacterial growth in $20 \%$ of the samples after treatment and
\end{abstract}

antibiogram showed higher sensibility to clindamycin, followed by espiramycin - all microorganisms were resistant to metronidazole.

Key words: periodontal disease, bacterial plaque, dogs, antibioticotherapy, clindamycin, methronidazole, espiramycin.

\section{INTRODUÇÃO}

A doença periodontal (DP) acomete o tecido de suporte do dente e o periodonto (WIGGS, 1997; DOMINGUES et al., 1999) e é a principal causa de perda de dentes em animais domésticos (WILLIAMS, 1997), com sua prevalência aumentando com a idade e atingindo cerca de $80 \%$ dos cães com mais de cinco anos (HARVEY \& EMILY, 1993; MARRETA, 2001). Os fatores predisponentes a essa afecção incluem raça, idade, genética, dieta e mastigação (HOFFMANN \& GAENGLER, 1996). Entretanto, é a presença de bactérias que influencia no processo contínuo da DP e atribui-se à placa bacteriana a causa da maioria das afecções bucais (DOMINGUES et al., 1999; LACERDA \& ALESSI, 2002; GIOSO \& CORREA, 2003; MEIRAet al., 2007).

A placa bacteriana, que pode ser supra ou subgengival, é constituída por microrganismos, células epiteliais, leucócitos e macrófagos (HAWKINS, 1997). A placa supragengival é geralmente composta por bactérias aeróbias Gram positivas, enquanto a placa

IFaculdade de Agronomia e Medicina Veterinária, Universidade de Brasília (UnB), 70910-900, Brasília, Distrito Federal, Brasil.

E-mail: stella.alves@gmail.com.*Autor para correspondência. 
subgengival é mais complexa, com presença de microrganismos Gram positivos e negativos, aeróbios e anaeróbios (HAWKINS, 1997; SCHWACHABDELLAOUI et al., 2000).

O surgimento e a progressão da DP caracterizam-se pelo desvio no tipo predominante da microflora subgengival (GROVE, 1997; BRUSCHI et al., 2006). Microrganismos aeróbios, como Actinomyces $\mathrm{e}$ Streptococcus, aderem à camada da placa madura, podendo acarretar retração ou hiperplasia gengival. Com a evolução do processo, a microbiota passa a ser anaeróbia e, geralmente, Gram negativa. As bactérias, por meio de seu metabolismo, produzem enzimas e toxinas que lesam as estruturas periodontais (LACERDA \& ALESSI, 2002) e iniciam uma resposta inflamatória, podendo contribuir para a proliferação bacteriana (WEST-HYDE \& FLOYD, 1997). Além da afecção bucal, as bactérias podem penetrar na corrente sanguínea e se acumular em outros órgãos, principalmente rins, fígado e coração, e neles causar lesões (DOMINGUES et al., 1999).

O tratamento da DP e das infecções odontogênicas fundamenta-se na remoção da placa bacteriana supra e subgengival, no polimento das coroas dentárias e na instituição de antibioticoterapia adequada (NELSON \& COUTO, 2001; SALINAS et al., 2006). Esta visa a reduzir ou suprimir a microbiota patogênica e, dessa forma, promover melhora clínica (GAETTI-JARDIM et al., 2007; MEIRA et al., 2007). Entretanto, não deve ser utilizada como terapia única, pois a permanência da placa bacteriana pode levar à mineralização e à formação de cálculo (HAWKINS, 1997). Quando os antibióticos são administrados de forma empírica, podem contribuir para o aparecimento de microrganismos resistentes a esses fármacos (SALINAS et al., 2006).

Drogas eficazes contra bactérias anaeróbias, a exemplo da clindamicina e da associação metronidazol + espiramicina, são preconizados no pré e no pósoperatório do tratamento periodontal (ADDY \& MARTIN, 2005; CARNEIRO et al., 2005; MEIRA et al., 2007). No entanto, um estudo comparativo quanto à eficácia da clindamicina e da associação metronidazol + espiramicina ainda não havia sido conduzido na medicina veterinária. Dessa forma, o objetivo deste trabalho foi estabelecer a microbiota da placa bacteriana subgengival de cães com DP, diagnosticados em exame clínico, e o efeito comparativo da antibioticoterapia sobre ela.

\section{MATERIAL E MÉTODOS}

Avaliaram-se 20 cães da raça labrador retriever, 14 machos e seis fêmeas, com peso médio de
$35,2 \mathrm{~kg}$ e idades entre um e oito anos. Os animais foram divididos aleatoriamente em dois grupos com 10 animais cada (G1 e G2) e identificados por numeração de um a 20.

$\mathrm{Na}$ consulta inicial (dia zero), os animais foram submetidos a exames pré-operatórios, com avaliação odontológica, exames físicos e laboratoriais e eletrocardiograma. À avaliação odontológica, os animais foram clinicamente classificados quanto ao grau de DP.

Cada animal foi submetido a duas coletas de amostra de placa bacteriana subgengival obtidas no mesmo sítio. A primeira coleta $(\mathrm{C} 1)$ foi realizada no dia zero e a segunda coleta (C2) 15 dias após o início da antibioticoterapia. Para o procedimento, utilizaram-se luvas de procedimento e tubos de papel para endodontia número 40, ambos estéreis, e contenção física. As coletas foram realizadas introduzindo-se os cones de papel no espaço subgengival em sítios periodontais que apresentavam sinais clínicos de inflamação.

Os cones com material subgengival foram encaminhados em meio tioglicolato (Biobrás ${ }^{\circledR}$ ) ao Laboratório de Microbiologia da Faculdade de Agronomia e Medicina Veterinária da Universidade de Brasília. No laboratório, as amostras foram incubadas a $37^{\circ} \mathrm{C}$ por 24 horas, em seguida, inoculadas em ágar sangue $\left(\mathrm{Oxoid}^{\circledR}\right)$, suplementado com $5 \%$ de sangue ovino desfibrinado e incubadas sob anaerobiose com uso de Jarra de Gaspak a $37^{\circ} \mathrm{C}$ por até 48 horas. As colônias crescidas foram identificadas por análise morfocelular (coloração de Gram) e testes bioquímicos, sendo, posteriormente, congeladas em caldo BHI $\left(\right.$ Difco $\left.^{\circledR}\right)+$ glicerol.

Para o teste de sensibilidade aos antimicrobianos, utilizou-se método de Kirby-Bauer de difusão em disco, com crescimento em caldo Müeller Hinton (Difco ${ }^{\circledR}$ ) até a densidade 0,5 da escala de MacFarland, e realizou-se plaqueamento em agar Müeller Hinton (Acumedia ${ }^{\circledR}$ ). Os antibióticos utilizados foram clindamicina $\left(\mathrm{Newprov}^{\circledR}\right)$, metronidazol $\left(\mathrm{Oxoid}^{\circledR}\right)$ e espiramicina $\left(\right.$ Oxoid $\left.^{\circledR}\right)$.

A antibioticoterapia foi iniciada três dias antes do tratamento periodontal e teve duração de sete dias. Os animais do G1 receberam clindamicina (Antirobe ${ }^{\circledR}$ ), na dose de $10 \mathrm{mg} \mathrm{kg}^{-1}$, e os do $\mathrm{G} 2$ receberam metronidazol + espiramicina $\left(\right.$ Periodontil ${ }^{\oplus}$ ), na dose de $12,5 \mathrm{mg} \mathrm{kg}^{-1}$ de metronidazol e $25 \mathrm{mg} \mathrm{kg}^{-1} \mathrm{de}$ espiramicina.

Para o tratamento periodontal, utilizaram-se acepromazina $\left(0,1 \mathrm{mg} \mathrm{kg}^{-1}\right)$ e morfina $\left(0,5 \mathrm{mg} \mathrm{kg}^{-1}\right)$ para medicação pré-anestésica, propofol $\left(3,0 \mathrm{mg} \mathrm{kg}^{-1}\right)$ para indução e anestesia inalatória (isofluorano e oxigênio) em circuito semifechado para manutenção. Realizou- 
se tratamento periodontal de rotina, com retirada de cálculo dentário e polimento dentário.

\section{RESULTADOS}

À avaliação clínica odontológica, seis (30\%) animais apresentaram grau discreto de doença periodontal (média de idade de três anos), dez (50\%) apresentaram grau moderado (média de quatro anos) e quatro $(20 \%)$ apresentaram grau avançado (média de 6,5 anos) (Figura 1).

$\mathrm{Na} \mathrm{C} 1,17(85 \%)$ amostras apresentaram crescimento bacteriano e foram isoladas 21 espécies; na $22,13(65 \%)$ apresentaram crescimento bacteriano e foram isoladas 15 diferentes espécies. Ou seja, após a antibioticoterapia, observou-se redução significativa no crescimento bacteriano $\left(\chi^{2}=4,53\right)$ e na quantidade de colônias isoladas $\left(x^{2}=7\right)$. Das $13(65 \%)$ amostras da C2 que apresentaram crescimento, sete $(53,84 \%)$ foram coletadas em animais do G1 (nove colônias isoladas) e seis $(46,15 \%)$ foram coletadas em animais do G2 (seis colônias isoladas) (Tabela 1).

As amostras 1, 3, 5, 6, 9, 11, 13, 14, 15, 17 e 19 (55\%) apresentaram crescimento de microrganismos diferentes na $\mathrm{C} 1$ e na $\mathrm{C} 2$; as amostras 2, 7, 8, 12, 16 e 20 $(30 \%)$ apresentaram crescimento bacteriano na $\mathrm{C} 1$, mas não apresentaram crescimento na $\mathrm{C} 2$; as amostras $4 \mathrm{e}$ $10(10 \%)$, por outro lado, não apresentaram crescimento na $\mathrm{C} 1$, mas apresentaram na $\mathrm{C} 2$; e a amostra $18(5 \%)$, por sua vez, não apresentou crescimento em nenhuma das duas coletas (Tabela 1).

Ao realizar o teste de sensibilidade aos antimicrobianos nas 21 colônias isoladas da $\mathrm{C} 1$, seis $(58,57 \%)$ foram sensíveis e duas $(9,52 \%)$ foram intermediárias à clindamicina, quatro $(19,04 \%)$ foram sensíveis e duas $(9,52 \%)$ foram intermediárias à espiramicina e todas foram resistentes ao metronidazol. Ao teste de sensibilidade aos antimicrobianos das 15 colônias da $\mathrm{C} 2$ do $\mathrm{G} 1$, uma $(6,66 \%)$ foi sensível à clindamicina; uma $(6,66 \%)$ foi sensível e uma $(6,66)$ foi intermediária à espiramicina; e todas foram resistentes ao metronidazol. No G2, todas as colônias foram resistentes a todos os antibióticos. Ao comparar a resistência bacteriana antes e após a antibioticoterapia, observou-se alteração significativa apenas quanto à sensibilidade dos microrganismos à espiramicina. Não se observou diferença significativa quanto à resistência bacteriana ao comparar antes e após a antibioticoterapia.

\section{DISCUSSÃO}

A placa bacteriana está presente na maioria das afecções bucais e sua correlação com a idade do animal pode auxiliar na prevenção e no tratamento da DP. Neste trabalho, observou-se maior frequência de grau avançado em animais mais velhos (Figura 1). SORENSEN et al. (1980), GENCO et al. (1998) eLOGAN \& BOYCE (1994) obtiveram resultados semelhantes, com índices mais baixos de placa em cães mais jovens. DUARTE \& LOTUFO (1997), em humanos, e REZENDE et al. (2004), em cães, também observaram correlação entre a DP e a idade do animal; porém, no segundo trabalho, em apenas $18,9 \%$ dos animais estudados, o índice de placa aumentou com o decorrer da idade. No trabalho de EURIDES et al. (1996), por outro lado, os índices de placa foram semelhantes nas diferentes faixas etárias de cães.

Os gêneros mais frequentemente isolados na $\mathrm{C} 1$ e na $\mathrm{C} 2$ foram Staphylococcus e Pasteurella. O Staphylococcus compõe a microbiota oral de cães

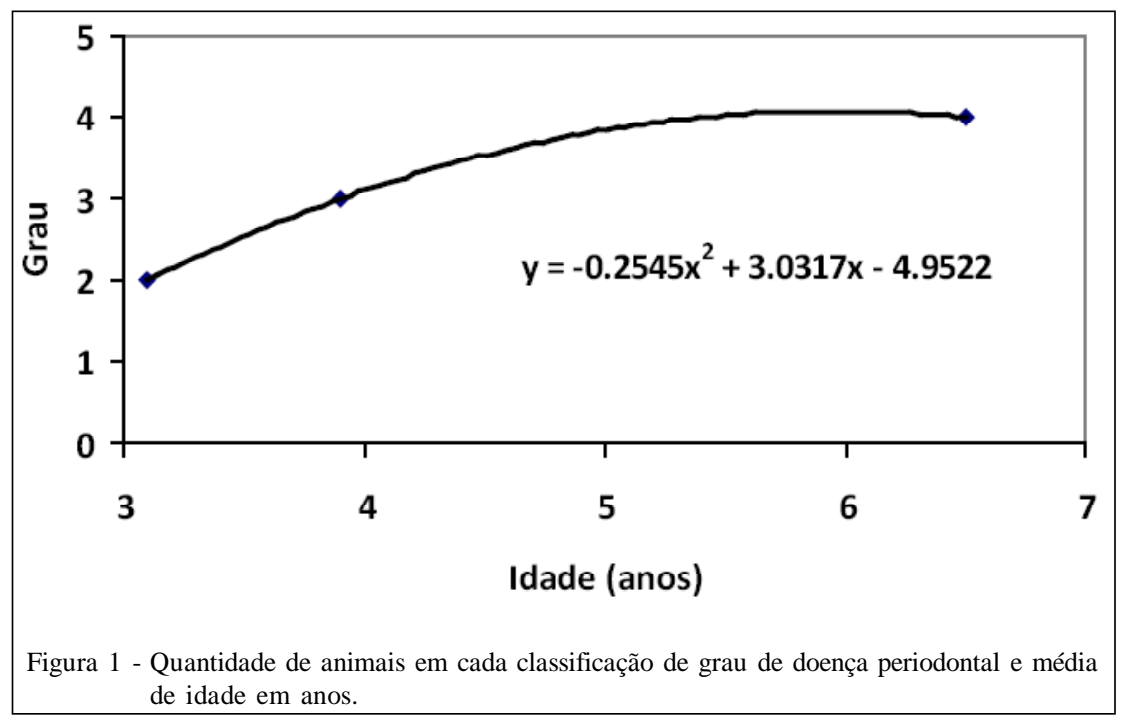

Ciência Rural, v.41, n.8, ago, 2011. 
Tabela 1 - Grau de doença periodontal e microrganismos isolados na C1 e na C2 nos animais do G1 (1 a 10) e do G2 (11 a 20)

\begin{tabular}{|c|c|c|c|}
\hline Animal & Grau da DP & Microorganismo na $\mathrm{C} 1$ & Microorganismo na $\mathrm{C} 2$ \\
\hline 1 & Moderado & Bacillus spp & Pasteurella caballi \\
\hline 2 & Moderado & Staphylococcus lentus & Sem crescimento bacteriano \\
\hline 3 & Discreto & Bacillus spp & Pasteurella caballi \\
\hline 4 & Discreto & Sem crescimento bacteriano & Staphylococcus gallinarum \\
\hline 5 & Moderado & Pasteurella multocida & Staphylococcus epidermidis \\
\hline 6 & Moderado & Pasteurella multocida & Escherichia coli \\
\hline 7 & Moderado & Staphylococcus epidermidis & Sem crescimento bacteriano \\
\hline 8 & Moderado & Staphylococcus lentus & Sem crescimento bacteriano \\
\hline 9 & Discreto & Staphylococcus lentus & Staphylococcus aureus \\
\hline 10 & Moderado & Sem crescimento bacteriano & $\begin{array}{l}\text { Streptococcus spp } \\
\text { Bacillus spp } \\
\text { Escherichia coli }\end{array}$ \\
\hline 11 & Discreto & Staphylococcus epidermidis & Pasteurella multocida \\
\hline 12 & Avançado & $\begin{array}{l}\text { Pasteurella pneumotropica } \\
\text { Pasteurella caballi }\end{array}$ & Sem crescimento bacteriano \\
\hline 13 & Moderado & Staphylococcus epidermidis & Pasteurella canis \\
\hline 14 & Discreto & Staphylococcus aureus & Pseudomonas spp \\
\hline 15 & Avançado & $\begin{array}{l}\text { Staphylococcus aureus } \\
\text { Bacillus spp }\end{array}$ & Escherichia coli \\
\hline 16 & Moderado & Staphylococcus gallinarum & Sem crescimento bacteriano \\
\hline 17 & Moderado & Levedura & Staphylococcus epidermidis \\
\hline 18 & Discreto & Sem crescimento bacteriano & Sem crescimento bacteriano \\
\hline 19 & Avançado & $\begin{array}{l}\text { Staphylococcus aureus } \\
\text { Pasteurella multocida }\end{array}$ & Bacillus spp \\
\hline 20 & Avançado & $\begin{array}{l}\text { Staphylococcus gallinarum } \\
\text { Streptococcus spp }\end{array}$ & Sem crescimento bacteriano \\
\hline
\end{tabular}

saudáveis e sua presença não indica necessariamente doença, pois possui baixo potencial periodontopatogênico (GAETTI-JARDIM, 2007). A alta incidência de Pasteurella, por sua vez, também foi relatada por BRAGA et al. (2005). Os autores deste último trabalho acreditam que a frequente contaminação causada por Pasteurella spp em feridas de mordidas de cães em humanos, demonstrada por TALAN et al. (1999), sugere a possibilidade de os cães serem reservatório natural dessa bactéria.

Foram isolados microrganismos em $95 \%$ dos cães avaliados, demonstrando que há presença de bactérias no espaço subgengival da maioria dos cães com DP. A redução significativa observada tanto no crescimento bacteriano quanto na quantidade de colônias isoladas após o tratamento sugere que os antibióticos atuaram no controle da microbiota relacionada à DP. Contudo, outros fatores devem ser considerados, como falha no crescimento bacteriano devido à técnica de coleta e redução de microrganismos após remoção mecânica da placa bacteriana.

Em $11(55 \%)$ animais, observou-se crescimento de microrganismos diferentes na $\mathrm{C} 1$ e na C2. Tais animais sofreram recolonização, que pode ocorrer mesmo quando a antibioticoterapia é efetiva. Em dois animais (10\%), não houve crescimento na C1, porém houve crescimento após a antibioticoterapia. Em um deles, foi isolado Staphylococcus spp, também por provável recolonização e, no outro, Streptococcus spp, Bacillus spp e Escherichia coli. O aparecimento desses três microrganismos pode ter resultado da queda de imunidade do animal após a C1 e/ou de contaminação secundária.

Em todos os cães com grau avançado de DP, a análise microbiana revelou a presença de duas espécies bacterianas distintas na $\mathrm{C} 1$, sugerindo maior 
diversidade na microbiota periodontal desses animais. BRAGA et al. (2005) obtiveram resultados semelhantes com isolamento de maior número de espécies bacterianas em animais com doença periodontal do que em animais saudáveis.

A clindamicina apresentou o melhor resultado quanto à sensibilidade, seguida da espiramicina - todos os microrganismos foram resistentes ao metronidazol. De acordo com LOESCHE et al. (1992), o insucesso no tratamento com metronidazol está relacionado a prescrições inadequadas, quando o agente etiológico não é identificado com precisão. No presente estudo, nenhuma colônia anaeróbia estrita foi isolada e, de acordo VERGANI et al. (2004), é sobre essas bactérias que o metronidazol tem ação excelente. Segundo os autores, tais microrganismos estão presentes em graus bastante avançados da doença, o que não ocorreu neste estudo. Isso demonstra que a clindamicina e a espiramicina podem ser mais indicadas em animais em estágio inicial da DP (predomínio de bactérias anaeróbias facultativas) e o metronidazol em estágios mais avançados (predomínio de bactérias anaeróbias estritas). Os trabalhos de AL-HARONI et al. (2006) e GAETTI-JARDIM et al. (2007) sustentam essa conclusão, pois o metronidazol foi o antibiótico mais eficaz frente às bactérias anaeróbias estritas, mas não apresentou atividade inibitória sobre as facultativas.

Em relação à maior quantidade de bactérias resistentes aos antibióticos na $\mathrm{C} 2$, considera-se que, como a coleta foi realizada após a antibioticoterapia, houve permanência de microrganismos resistentes ao tratamento. Contudo, não se pode descartar a possibilidade de aquisição de resistência por parte dos microrganismos.

\section{CONCLUSÃO}

Observou-se crescimento bacteriano subgengival na maioria dos cães com DP e houve uma correlação positiva entre a severidade da DP e a idade dos animais. Todos os microrganismos isolados foram anaeróbios facultativos. Houve redução significativa do crescimento bacteriano nas amostras da $\mathrm{C} 2$, provavelmente em decorrência da associação antibioticoterapia e remoção mecânica da placa bacteriana. Ao teste de sensibilidade aos antimicrobianos, o maior índice de sensibilidade foi observado frente a clindamicina, seguido da espiramicina; todos os microrganismos foram resistentes ao metronidazol. Os principais microrganismos isolados foram Staphylococcus spp e Pasteurella spp, mesmo após a antibioticoterapia, o que pode sugerir resistência aos antibióticos e/ou presença natural dessas bactérias na cavidade oral de animais saudáveis.

\section{REFERÊNCIAS}

ADDY, L.D.; MARTIN, M.V. Clindamycin and dentistry. British Dental Journal, v.199, n.1, p.23-26, 2005. Disponível em: <http://www.nature.com/bdj/journal/v199/n1/ abs/4812535a.html>. Acesso em: 15 abr. 2011. doi: 10.1038/ sj.bdj. 4812535 .

AL-HARONI, M.H. et al. Prevalence of subgingival bactéria resistant to aminopenicillins and metronidazole in dental patients from Yeman and Norway. International Journal of Antimicrobial Agents, v.27, p.217-223, 2006. Disponível em: <http://www.ijaaonline.com/article/S09248579\%2805\%2900330-4/abstract>. Acesso em: 15 abr. 2011. doi: $10.1016 /$ j.ijantimicag.2005.10.011.

BRAGA, C.A.S.B. et al. Isolamento e identificação da microbiota periodontal de cães da raça Pastor Alemão. Ciência Rural, v.35, n.2, p.385-390, 2005. Disponível em: <http://www.scielo.br/ $\mathrm{pdf} / \mathrm{cr} / \mathrm{v} 35 \mathrm{n} 2 / \mathrm{a} 22 \mathrm{v} 35 \mathrm{n} 2 . \mathrm{pdf}>$. Acesso em: 15 abr. 2011.

BRUSCHI, M.L. et al. Sistemas de liberação de fármaco intrabolsa periodontal. Brazilian Journal of Pharmacetical Sciences, v.42, n.1, p.29-47, 2006. Disponível em: <http:// www.scielo.br/pdf/rbcf/v42n1/29857.pdf>. Acesso em: 15 abr. 2011. doi: 10.1590/S1516-93322006000100004.

CARNEIRO, S.M.B.S. et al. Uso do metronidazol como medicação em dentes com necrose pulpar e reação periapical - Relato de caso. Odonto Ciência, v.20, n.47, p.78-82, 2005. Disponível em: <http://bases.bireme.br/cgi-bin/ w x is lind.exe/iah/online/? Is is S cript =i ah/ iah. $x$ is $\& s r c=$ google $\&$ base $=$ ADOLEC $\&$ lang $=p \&$ nextAction $=1$ nk\&exprSearch $=413495 \&$ indexSearch $=$ ID $>$. Acesso em: 15 abr. 2011.

DOMINGUES, L.M. et al. Microbiota saprófita associada à doença periodontal em cães. Arquivo Brasileiro de Medicina Veterinária e Zootecnia, v.51, n.4, p.232-239, 1999. Disponível em: <http:// www.scielo.br/scielo.php? script $=$ sci_arttext $\&$ pid $=$ S0 102 09351999000400007>. Acesso em: 15 abr. 2011. doi: 10.1590/ S0102-09351999000400007.

DUARTE, C.A.; LOTUFO, R.F.M. Etiopatogenia da doença periodontal e cárie - Importância da placa bacteriana. Prevenção na clínica odontológica. São Paulo: Artes Médicas, 1997. Cap.4, p.30-50.

EURIDES, D. et al. Placa bacteriana dentária em cães. Ciência Rural, v.26, n.3, p.419-422, 1996. Disponível em: <http:// tinyurl.com/3p4bszh>. Acesso em: 15 abr. 2011.

GAETTI-JARDIM, J.E. et al. Susceptibilidade de bactérias anaeróbias isoladas de infecções periplantares e periodontais ao metronidazol, lincosaminas, macrolídeos e tetraciclina. Odonto Ciência, v.22, n.56, p.131-137, 2007. Disponível em: <http:/ /bases.bireme.br/cgi-bin/wxislind.exe/iah/online/?IsisScript=iah/ iah.xis\&src=google\&base $=$ LILACS\&lang=p\&nextAction=lnk\&expr Search=472489\&indexSearch=ID>. Acesso em: 15 abr. 2011.

GENCO, C.A. et al. Animal models for porphyromonas gingivalismediated periodontal disease. Trends in Microbiology, v.6, 
n.11, p.444-449, 1998. Disponível em: <http://tinyurl.com/ $4 \times v 61 q z>$. Acesso em: 15 abr. 2011. doi: 10.1016/S0966842X(98)01363-8

GIOSO, M.A.; CORREA, H.L. Odontologia veterinária. Medvep, v.1, n.1, p.1-7, 2003.

GROVE, T.K. Odontologia. Afecção periodontal. In: ETTINGER, S.J.; FELDMAN, E.C. Tratado de medicina interna veterinária. Moléstias do cão e do gato. 4.ed. São Paulo: Manole, 1997. V.2, p.1523-1524.

HARVEY, C.E.; EMILY, P.P., Periodontia. In.: ROZA, M.R Odontologia em pequenos animais. Rio de Janeiro: L.F. Livros de Veterinária, 2004. p.119-134.

HAWKINS, B.J. Periodontal disease in dogs and cats. In MARRETTA, M.S. et al. Veterinary dentistry: managing the dental patient. Orlando: Veterinary Learning Systems, 1997. p.17-22.

HOFFMANN, T.; GAENGLER, P. Periodontia. In.: ROZA, M.R. Odontologia em pequenos animais. Rio de Janeiro: L.F. Livros de Veterinária, 2004. p.119-134

LACERDA, M.S.; ALESSI, A.C. Avaliação histobacteriológica de dentes envolvidos com doença periodontal em cães, após raspagem periodontal. Journal of Bioscience, v.18, n.1, p.137-149, 2002. Disponível em: <http://www.seer.ufu.br/ index.php/biosciencejou rnal/article/viewFile/6399/4136>. Acesso em: 15 abr. 2011.

LOESCHE, W.J. et al. Metronidazole in periodontitis: reduced need for surgery. Journal of Clinical Periodontology, v.19, n.2, p.103-112, 1992. Disponível em: <http://www.mendeley.com/ research/metronidazole-periodontitis-reduced-need-surgery/>. Acesso em: 15 abr. 2011. doi: 10.1111/j.1600051X.1992.tb00448.x.

LOGAN, E.L.; BOYCE, E.N. Oral health assesment in dogs: parameters and methods. Journal of Veterinary Dentistry, v.11, n.2, p.58-63, 1994. Disponível em: <http://www.ncbi.nlm.nih.gov/pubmed/9693614>. Acesso em: 15 abr. 2011.

MARRETA, S.M. Periodontia. In.: ROZA, M.R. Odontologia em pequenos animais. Rio de Janeiro: L.F. Livros de Veterinária, 2004. p.119-134.

MEIRA, A.L.T. et al. Uso de antimicrobianos locais em periodontia: Uma abordagem crítica. Periodontia, v.12, n.1, p.83-89, 2007. Disponível em: 〈http://tinyurl.com/3z7eo8w〉. Acesso em: 15 abr. 2011

NELSON, R.W.; COUTO, C.G. Distúrbios da cavidade bucal, da faringe e do esôfago. In: ______ _____. Medicina interna de pequenos animais. 2.ed. Rio de Janeiro: Guanabara Koogan, 2001. p.324.

SALINAS, M.B. et al. Susceptibilidad antibiótica de las bacterias causantes de infecciones odontogénicas. Medicina oral, patologia oral y cirurgia bucal, v.11, n.1, p.70-75, 2006. Disponível em: <http://dialnet.unirioja.es/servlet/ articulo?codigo $=3058797>$. Acesso em: 15 abr. 2011

SORENSEN, W.P. et al. Periodontal disease in the beagle dog. Journal of Periodontal Research, v.15, n.4, p.380-389, 1980. Disponível em: <http://onlinelibrary.wiley.com/doi/ 10.1111/j.1600-0765.1980.tb00295.x/abstract>. Acesso em: 15 abr. 2011. doi: 10.1111/j.1600-0765.1980.tb00295.x.

SCHWACH-ABDELLAOUI, K. et al. Local delivery of antimicrobial agents for the treatment of periodontal diseases. European Journal of Pharmaceutics and Biopharmaceutis, v.500, p.83-99, 2000. Disponível em: <http://research.rmutp.ac.th/ paper/cu/article08.pdf>. Acesso em: 15 abr. 2011. doi: 10.1208/ ps040420.

TALAN, D. A. et al. Bacteriologic analisis of infected dog and cat bites. New England Journal of Medicine, v.340, n.2, p.85-92, 1999. Disponível em: <http://www.nejm.org/doi/full/ 10.1056/NEJM199901143400202>. Acesso em: 15 abr. 2011.

VERGANI, S.A. et al. Systemic use of metrhonidazole in the treatment of chronic periodontitis: a pilot study using clinical, microbiological and enzymatic evaluation. Brazilian Oral Research, v.18, n.2, p.121-127, 2004. Disponível em: <http:/ /tinyurl.com/3ntc6yw>. Acesso em: 15 abr. 2011.

WEST-HYDE, L.; FLOYD, M. Odontologia. In: ETTINGER, S.J.; FELDMAN, E.C. Tratado de medicina interna veterinária. Moléstias do cão e do gato. 4.ed. São Paulo: Manole, 1997. V.2, p.1523-1524.

WIGGS, R.B. Doença periodontal em cães e gatos: profilaxia e manejo dietético. Clínica Veterinária, Ano II, n.8, p.24-28, 1997.

WILLIAMS, R.C. Odontologia. Afecção periodontal. In: ETTINGER, S.J.; FELDMAN, E.C. Tratado de medicina interna veterinária. Moléstias do cão e do gato. 4.ed. São Paulo: Manole, 1997. V.2, p.1523-1524. 